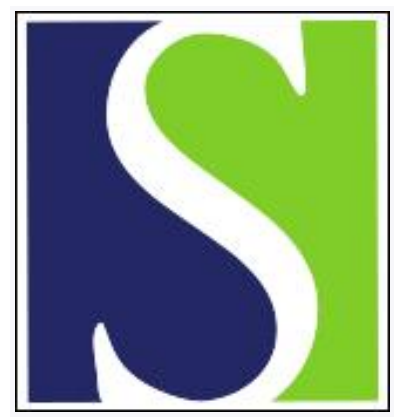

Scand J Work Environ Health 2013;39(5):456-467

https://doi.org/10.5271/sjweh.3361

Published online: 08 Apr 2013, Issue date: 01 Sep 2013

The effectiveness of a construction worksite prevention program on work ability, health, and sick leave: results from a cluster randomized controlled trial

by Oude Hengel KM, Blatter BM, van der Molen HF, Bongers PM, van der Beek AJ

This study is new in investigating an intervention that targeted both physical as well as psychosocial factors among construction workers on work ability, health, and sick leave. Because no significant differences were found between the two study groups, further implementation of this intervention is not recommended at this time.

Affiliation: Netherlands Organisation for Applied Scientific Research TNO, PO Box 718, 2130 AS, Hoofddorp, The Netherlands. karen.oudehengel@tno.nl

Refers to the following texts of the Journal: 2002;28(2):85-93 2004;30(1):56-63 2005;31(5):394-400 2007;33(5):351-357

2009;35(1):1-5 2009;35(5):325-333 1991;17 suppl 1:87-93

2010;36(5):404-412 2012;38(5):467-475

The following articles refer to this text: 2013;39(5):427-429; 2018;44(2):134-146; 2020;46(2):218-227

Key terms: construction; construction industry; construction worker; effectiveness; empowerment; health; health; health promotion; physical workload; prevention; randomized controlled trial; sick leave; sustainable employability; work ability; worksite

This article in PubMed: www.ncbi.nlm.nih.gov/pubmed/23567980

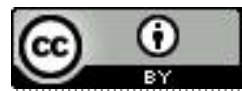




\title{
The effectiveness of a construction worksite prevention program on work ability, health, and sick leave: results from a cluster randomized controlled trial by Karen M Oude Hengel, PhD,1, 2 Brigitte M Blatter, PhD,1,2 Henk F van der Molen, PhD, , 4 Paulien M Bongers, PhD, ${ }^{1,2,5}$ Allard J van der Beek, PhD ${ }^{2,5}$
}

\begin{abstract}
Oude Hengel KM, Blatter BM, van der Molen HF, Bongers PM, van der Beek AJ. The effectiveness of a construction worksite prevention program on work ability, health, and sick leave: results from a cluster randomized controlled trial. Scand J Work Environ Health. 2013;39(5):456-467. doi:10.5271/sjweh.3361
\end{abstract}

\begin{abstract}
Objective This study aimed to investigate the effectiveness of a prevention program on work ability, health, and sick leave targeted at construction worksites.

Methods A total of 15 departments ( $N=297$ workers) from 6 construction companies participated in this cluster randomized controlled trial and were randomly allocated to the intervention ( 8 departments; $\mathrm{N}=171$ workers) or control ( 7 departments; $\mathrm{N}=122$ workers) group. The intervention consisted of two individual training sessions with a physical therapist aimed at lowering the physical workload, a rest-break tool to improve the balance between work and recovery, and two empowerment training sessions to increase the worker's influence at the worksite. Data on work ability, physical and mental health status, and musculoskeletal symptoms were collected at baseline, and at 3, 6, and 12 months follow-up. Sick leave data were obtained from the companies.
\end{abstract}

Results Overall, no differences in work ability $[\beta 0.02,95 \%$ confidence interval $(95 \% \mathrm{CI})-0.34-0.37]$ or physical and mental health status ( $\beta-0.04,95 \% \mathrm{CI}-1.43-1.35$, and $\beta 0.8095 \% \mathrm{CI}-0.51-2.11$, respectively) were found between the intervention and control group. The intervention showed an overall decline in musculoskeletal symptoms (ranging from OR $0.68,95 \% \mathrm{CI} 0.34-1.33$, to OR $0.86,95 \% \mathrm{CI} 0.47-1.57$ ) and long-term sick leave (OR 0.44, 95\% CI 0.13-1.26) among construction workers. Both reductions were not statistically significant.

Conclusion The prevention program seemed to result in a beneficial but not statistically significant decline in the prevalence of musculoskeletal symptoms and long-term sick leave among construction workers, but showed no effects with regard to work ability, physical health, and mental health.

Key terms construction industry; construction worker; empowerment; health promotion; physical workload; sustainable employability.

In the next decades, a shortage of workers is expected in the Dutch construction industry due to a delay in young workers entering the labor force (1). In addition, many workers are expected to leave the labor force before the official retirement age (2). The age of retirement among Dutch construction workers has been strongly influenced by collective agreements, which offer the opportunity of retiring at the age of 62 , instead of the official retirement age of 65 . In order to face the challenges of the expected shortages, it is considered necessary that construction workers extend their working life until their official retirement age. However, due to their physical workload, construction workers run an increased risk for sick leave (3) and disability pension (4). Thus, retaining the labor force in the construction industry is not only a matter of raising the retirement age in collective agreements, but also a matter of improving the ability and intention of workers to remain in the labor force (5).

To support the sustainable employability of construction workers, policies and intervention programs focusing on work ability and health appear to be useful. Focusing on these factors could be beneficial as they are

1 Netherlands Organisation for Applied Scientific Research TNO, Hoofddorp, The Netherlands.

2 Body@Work, Research Center on Physical Activity, Work and Health, TNO-VU/VUmc, The Netherlands.

3 Coronel Institute of Occupational Health, Academic Medical Center, University of Amsterdam, Amsterdam, The Netherlands.

4 Arbouw, Harderwijk, The Netherlands.

5 Department of Public and Occupational Health, EMGO Institute for Health and Care Research, VUmc, Amsterdam, The Netherlands.

Correspondence to: KM Oude Hengel, Netherlands Organisation for Applied Scientific Research TNO, PO Box 718, 2130 AS, Hoofddorp, The Netherlands. [E-mail: karen.oudehengel@tno.nl] 
major contributors of sustainable employability. Previous studies have shown that blue-collar workers with a poor work ability are at an increased risk for early retirement (6), and poor work ability predicted long-term sick leave $(3,4,6)$ and disability pensions $(4,7)$. Regarding health, a poor physical and mental health status was associated with a diminished ability to continue working until the age of 65 (8), whereas other studies have also found an association between physical health and early retirement (9) and disability pensions $(9,10)$.

To date, we have found only one study that aimed to improve work ability of construction workers at risk for early retirement and disability pensions (11). This six-month counseling and education program showed no significant differences on work ability or disability pensions. The authors hypothesized that a more comprehensive intervention starting at an earlier stage in the working lives of construction workers could potentially be more effective.

As a result, we developed a comprehensive prevention program using the intervention mapping approach, meaning that theoretical information from the literature was combined with practical information from stakeholders $(12,13)$. The program consisted of three components aiming to improve the health and work ability of construction workers. Construction workers run an increased risk for musculoskeletal symptoms $(14,15)$, lower work ability (16), and sick leave (3) due to high physical job demands, such as awkward postures and repetitive movements (17). Consequently, as a first step, a physical therapist made two individual visits to the worksites with the aim of lowering physical work demands. As a consequence of the high physical work demands, older construction workers experience more fatigue and a higher need for recovery after work (18). Therefore, the second intervention component, a rest-break tool, was introduced to improve the balance between the physical workload and need for recovery during and after work. Finally, as the literature and focus groups showed that more job control, job satisfaction, and social support from management at construction worksites might improve work ability (16) and reduce sick leave (3), two group empowerment training sessions were organized as the third intervention component in order to achieve a cultural change at the worksites. In a recent publication, the process of this worksite prevention program was evaluated (19).

The objective of the present study was to evaluate the effectiveness of the worksite prevention program within a cluster randomized controlled trial (RCT). Cluster randomization was considered as the best strategy in order to avoid intervention group contamination, accommodate the worksite program, and obtain maximal cooperation of employers and employees. We hypothesized that the worksite prevention program targeted at construction workers could improve their work ability and mental and physical health status. We also hypothesized a decline in the prevalence of musculoskeletal symptoms and long-term sick-leave in the intervention group.

\section{Methods}

\section{Study design and population}

The clustered RCT was conducted in 15 departments of 6 Dutch construction companies, specialized in house, commercial, or industrial building. The project group recruited the construction companies by phone through a mailing list and personal contacts within the research group. All workers of these companies performing actual construction work and having an official contract with the company were invited to participate in the study. All participants had to be able to complete questionnaires written in the Dutch language and sign a written informed consent. No exclusion took place based on age or gender. The Medical Ethics Committee of the VU University Medical Center (Amsterdam, The Netherlands) approved the study protocol. More details on the study design and methods have been described elsewhere (13).

\section{Randomization, blinding, and sample size}

Cluster randomization took place at the level of department within each company. All departments within the companies participated in the project and were randomly assigned to the worksite prevention program or the control group (ie, no intervention). A research assistant, who had no prior information about the departments, performed the randomization procedure. For practical reasons, randomization took place before baseline measurement. The principal researcher recruited the construction workers at the worksites and, as a result, the construction workers, their supervisors and the trainers could not be blinded to the allocation. The sample size was calculated based on the number of cases needed to identify an effect on health status. The Short-Form Health Survey (SF-36) $(20,21)$ was used for the sample size calculation because the outcome measure SF-12 has rarely been used in intervention studies among the general population. Previous studies presented effect sizes ranging from 0.58-0.96 (22). Due to the study's design, a certain loss of efficiency associated with cluster randomization relative to individual randomization was taken into account (23). Therefore, an effect size of 0.40 was considered to be the lower boundary of a medium effect size (24). This effect size can be detected with two 
groups of 100 (with a power of $80 \%$ and a two-tailed significance level of 5\%). Taking a loss to follow-up of about $10 \%$ into account, 220 construction workers were needed at baseline.

\section{Intervention}

The intervention was developed according to the intervention mapping protocol (25), a six-step protocol that facilitates a stepwise process for theory- and evidencebased development of health promotion programs (12). The six-month prevention program consisted of both a physical and mental component.

The physical component comprised two individual training sessions of approximately 30 minutes, run by a physical therapist, and a rest-break tool. During the first session at the worksite, a quick scan questionnaire was followed by a 15-minute observation at the workplace. Based on this, the physical therapist made a maximum of three individually targeted recommendations on how to reduce the physical workload (eg, improvements in work techniques, work methods, and/or rest breaks) that were inscribed on a pocket-size card. During the second training session, which took place four months after the first, the physical therapist discussed the workers' experiences to date and evaluated the impact of the earlier advice with the worker. During the first visit, the physical therapist also introduced the rest-break tool to raise awareness about the importance of reducing fatigue by taking flexible rest breaks and stimulating the actual implementation of alternative rest breaks. The rest-break tool is a flowchart addressing: (i) workers' expectations about their fatigue at the end of the working day, (ii) short-term advice on mini rest breaks or an additional break of ten minutes, (iii) the possible causes of fatigue, and (iv) long-term advice on how to lower fatigue structurally. The workers were asked to complete the tool weekly, alone or with colleagues, and to discuss the results with their supervisor.

For the mental component, the construction workers received two interactive empowerment training sessions of approximately one hour in the construction trailer at the worksite. The training sessions aimed to improve construction workers' influence at the worksite regarding: (i) taking responsibility for their own health, (ii) discussing with colleagues about the responsibility for their own behavior (eg, taking rest breaks, asking for assistance during physically demanding work tasks), and (iii) improving the communication with the supervisor. The first training session consisted of five steps, in which the workers created a list of topics they wanted to address during the intervention period, resulting in a signed action plan. After four months during a follow-up meeting, the empowerment trainer and workers discussed and reconsidered the action plan as well as the results that were achieved. More details on the development and content of the intervention have been described elsewhere (13).

\section{Outcomes measures}

The present study investigated the effectiveness of the intervention on primary outcomes (ie, work ability, and mental and physical health status) and on two secondary outcomes (ie, the occurrence of musculoskeletal symptoms and sick leave). Other outcomes measures that were assessed but not presented in this paper included short-term outcomes such as work engagement, physical workload, need for recovery, and social support. All workers' outcome measures were obtained by questionnaires that were generally collected at the worksites. The baseline measurement took place after randomization, and follow-up measurements were performed at 3, 6 , and 12 months after baseline. Sick leave data were gathered from continuous registration systems of the companies after 12 months of follow-up.

Work ability. Work ability was measured using the Work Ability Index (WAI), which originally consists of seven items (26). Different studies have shown that the reliability and validity of WAI vary from acceptable to good $(27,28)$. Because sub-items of the WAI could also be used as a simple indicator for assessing the status and progress of work ability $(29,30)$, two of the seven items were assessed in the present study: current work ability (one question), and work ability in relation to physical and mental job demands (two questions). A total score of the WAI (range 2-20) was obtained by adding the weight scores of these individual items (31).

Health. Health status was assessed using the SF-12 (32, 33). This measure provided two weighted scores assessing physical health status and mental health status (34). Different studies among general populations (respondents aged $\geq 15$ years) have shown adequate reliability and validity of the SF-12 $(33,35)$. The mean physical and mental health status of the general population is 50 , with a standard deviation of 10 (35). A higher score means a better physical or mental health.

Musculoskeletal symptoms were measured using the Dutch Musculoskeletal Questionnaire (DMQ) $(36,37)$. The workers were asked to rate the occurrence of pain or discomfort in the neck, shoulders, upper and lower back, elbows, wrists/hands, hips/thighs, knees and ankles/feet during the previous seven days using a 4-point scale (never, sometimes, frequent, and prolonged). These regions were grouped into four larger body regions: back (upper and lower back), neck/shoulders, and upper (elbows and wrist/hands) and lower extremities (hips/ thighs, knees and ankles/feet). For each body region, workers were classified as having musculoskeletal 
symptoms if they answered "frequent" or "prolonged" on $\geq 1$ questions, whereas the others were classified as having no musculoskeletal symptoms.

Sick leave. Sick leave data were obtained from databases of the six companies. For the analyses, sick leave data from three periods of six months were used: prior to the intervention, during the intervention, and after the intervention. Sick leave was defined as the total number of working days during the six-month period of concern during which the workers were on sick leave. Because of the skewed distributions, sick leave was dichotomized into 6-month prevalence of no or short-term sick leave (0-5 days) and long-term sick leave ( $\geq 6$ days).

\section{Statistical analysis}

All analyses were performed according to the intention-to-treat principle. Baseline differences between the intervention and control group were checked by unpaired Student t-test (continuous variables) and Pearson's Chi-square test (dichotomous variables) using the Statistical Package of Social Sciences, version 17.0 (SPSS Inc, Chicago, IL, USA). As departments within the companies, rather than workers, were randomized, multilevel regression analyses were performed for all outcome variables using MlwiN, version 2.18 (Center for Multilevel Modeling, University of Bristol, UK). Multilevel regression analyses are extended linear regression analyses that are most appropriate for analyzing longitudinal data sets containing correlated or clustered observations and unbalanced data [ie, participants were not equally divided among departments (38)]. Four levels of clusters were identified for the current dataset: time (four measurements), worker $(\mathrm{N}=293)$, department $(\mathrm{N}=15)$, and company $(\mathrm{N}=6)$.

For the multilevel analyses in the current study, we first checked if it was necessary to cluster the data within departments and companies for our dataset. To correct for clustering, multilevel analyses adds a single variance parameter of the different regression lines of a level (eg, 15 different departments or 6 companies) to the regression analyses in a new model. Next, the chi-square likelihood-ratio test was used to assess the significant differences between the two models (with and without an additional level). This assessment is needed to determine which of the two models fits better. Based on this assessment, the multilevel analyses for two primary outcomes (ie, work ability and physical health status) needed to be corrected for time, worker, and company level. Clustering at department or company level was not needed for mental health status. However, to be consistent, correcting for company level was taken into account for mental health status as well. For the secondary outcomes (ie, musculoskeletal symptoms and sick leave), multilevel analyses only needed to be corrected for time and workers. Clustering at department or company level did not result in a better fit of the model for the secondary outcomes.

Next, for the primary outcomes, the dependency of observations [intracluster correlation coefficient (ICC)] was calculated for workers within companies using the output from MLwiN. The ICC was calculated by dividing the between-company variance by the total variance, which in turn is calculated by summation of the between-company and within-company variances (38).

After building the multilevel models, linear mixed models were used to evaluate the effects on work ability and mental and physical health, while logistic mixed models were used to evaluate the effects on musculoskeletal symptoms and sick leave. For each outcome variable, two analyses were performed: (i) a crude analysis to determine the differences between the intervention and control group at 3,6, and 12 months of follow-up, adjusted for the corresponding baseline outcome variable, and (ii) the analysis as described above but adjusted for potential confounders [ie, age and educational level (ie, primary school, lower and intermediate secondary education versus higher secondary education intermediate vocational and university)]. Confounding was considered if $>10 \%$ change occurred in the regression coefficient. Effect modification was considered for age and educational level. A P-value $<0.05$ of the interaction term was used to indicate effect modification. For all analyses, the intervention effect of interest was between group and measurement time, expressed in betas $(\beta)$ and $95 \%$ confidence intervals $(95 \% \mathrm{CI})$ for the linear regression analyses and odds ratios (OR) and $95 \%$ CI for the logistic regression analyses.

\section{Results}

\section{Participant flow}

Figure 1 outlines the complete flow of the participants from the six companies that were recruited between March 2008 and December 2009. When a company agreed to participate in the program, construction workers of the company were approached at the worksite and received the baseline questionnaire. During recruitment, 37 companies expressed an interest in the intervention program and 6 actually participated; departments in each company were randomized to either the intervention (8 departments, $\mathrm{N}=171$ ) or control (7 departments, $\mathrm{N}=122$ ) group (figure 1). Departments varied in size between 9-28 and 4-30 workers in the intervention and control groups, respectively. All intervention group participants were working in departments specialized in house and 


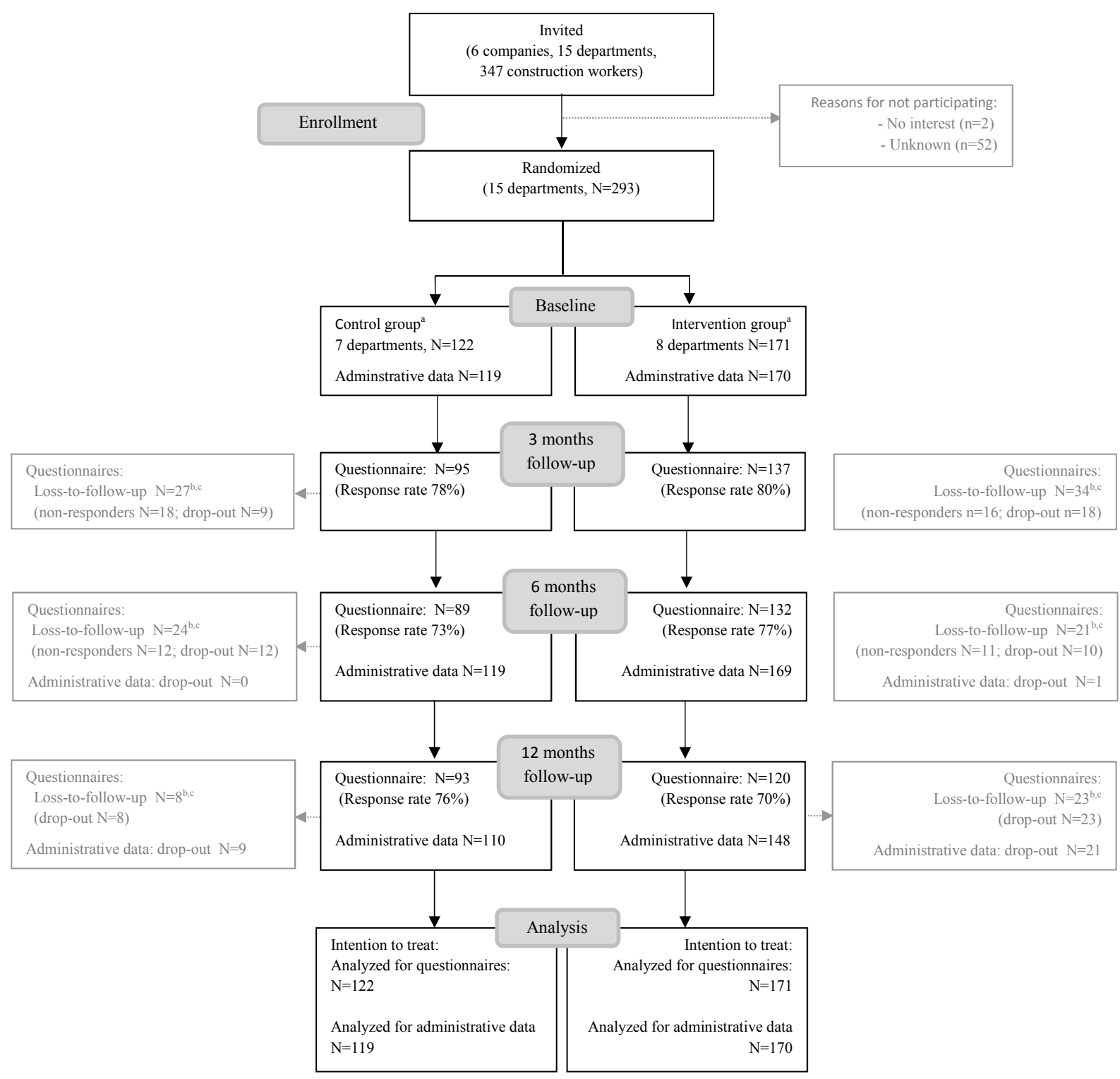

Figure 1. Flow diagram of the participants through the phases of the trial. a Sick leave data were not available for four workers: 3 in the intervention and 1 in the control group. ${ }^{b}$ Workers who were lost to follow-up due to non-response were included again in the following measurements. ${ }^{c}$ Drop-out was defined as workers who stopped participating in follow-up measurements.

utility building. Three of these departments consisted largely of carpenters whereas the other departments consisted of carpenters, bricklayers, tilers, and plasterers. Regarding the control group, one department was specialized in renovation and maintenance whereas the other departments focused on house and utility building. In two departments, the majority of workers were carpenters, whereas the professions varied in the other departments. None of the departments in both the intervention and control group were lost-to-follow-up.

The baseline questionnaire was distributed to 347 construction workers, 293 (84\%) of whom responded.
After 12 months, 29 (24\%) of control and $51(30 \%)$ of intervention group workers were lost-to-follow-up. These subjects had a significantly lower education than the remaining participants. The main reasons for lossto-follow-up were: sick leave, the (un)voluntary ending of the contract, or discharge due to the economic crisis.

\section{Baseline characteristics}

The baseline characteristics of construction workers in the intervention and control group are presented in table 1. No significant differences regarding age, gender, 
profession, work ability, physical health, and the occurrence of musculoskeletal symptoms were found between the two groups. However, construction workers in the intervention group were higher educated and showed a slightly higher mental health status compared to those in the control group.

\section{Effectiveness of the intervention}

Work ability. Table 2 presents the means for work ability at baseline and at 3,6, and 12 months follow-up per study group, as well as the results of the multilevel linear regression analyses. No overall intervention effect or an effect at any of the time measurements was found.

Health. The intervention did not result in significant effects on either physical or mental health status (table 2). With respect to musculoskeletal disorders, construction workers in the intervention group reported, in general, less symptoms of the back, neck/shoulders, upper and lower extremities at 3, 6, and 12 months follow-up compared to those in the control group (table 3 ). However, neither the overall intervention effects nor the effects on any of the time measurements were statistically significant.

Sick leave. Table 3 shows the values for sick leave at baseline and 6 and 12 months follow-up, as well as the effectiveness of the intervention on sick leave. For the overall effect and both follow-up periods, the 6-month prevalence of long-term sick leave was lower in the intervention compared to control group. However, this was not statistically significant.

\section{Discussion}

The preventive intervention in the current study was not effective in improving work ability or physical and mental health status. However, the intervention showed a decline in the prevalence of musculoskeletal symptoms and long-term sick leave among construction workers, although both not statistically significant.

To our knowledge, this is the first study that evaluated an intervention in the construction industry that targeted both physical and psychosocial factors. These factors were considered important for the labor force participation of construction workers (12) and have also been raised by previous researchers $(9,39)$. Until now, most health promotion programs in the construction industry have focused on improving the physical health of construction workers through a lifestyle program (40-42) or by decreasing the physical work demands by means of ergonomic measures (43).
The intervention was performed in a cluster RCT according to corresponding quality standards (44). The study's strengths include randomization, the control group, and the intention-to-treat principle. This standardized design reduced the effects of possible interference from other initiatives promoted by the companies during the intervention, and allows for an interpretation of the effects of this prevention program. Moreover, the randomization at department level minimized the risk of contamination. Avoiding contamination is especially important in the construction industry where workers operate at temporary and mobile worksites. Because randomization took place at department level, multilevel analyses were performed in which regressions models were checked for clustering at department and company level. The regression models showed that correcting for department level was not necessary for any of the outcomes, whereas only work ability and physical health status needed to be corrected for company level. Moreover, the presented ICC for the primary outcomes were between $0.01-0.06$ indicating a low dependency of observations within companies (38). Thus, even though randomization took place at department level within companies, the dependency of the observations mainly was at individual level. Second, the generalizability of the study findings towards construction workers is strengthened by the fact that the current study population consisted of construction workers with different professions, from all over the Netherlands and of all ages. Lastly, sick leave data were gathered from the continuous registration systems, which eliminated information or recall bias and limited loss-to-follow up.

Some limitations deserve attention as well. First, most data were obtained from questionnaires collected at the worksite. As a result, data were self-reported inducing a potential risk of bias due to the desire to give socially acceptable answers. The second concern is the limited statistical power. We chose to base the power calculation on the number of cases needed to identify an effect on mental and physical health status and not the other outcome measures. Additionally, the loss-tofollow-up was higher than expected due to the economic crisis (ie, workers in one company were laid-off or worked part-time) and because workers were on sickleave during the measurements. It should be noticed that, even without the economic crisis, the loss-to-follow-up of $10 \%$ in the sample size calculation appeared to be an underestimation. Third, a relative high rate of data was missing for the physical and mental health score because workers did not complete all 12 items of the questionnaire.

In accordance with previous studies on work ability $(11,45,46)$ and mental and physical health status (47), the intervention in the current study showed no improvements on these outcomes. The lack of statisti- 
Table 1. Baseline characteristics of the study population ( $N=293$ ) [SD=standard deviation]

\begin{tabular}{|c|c|c|c|c|c|c|c|c|}
\hline & \multicolumn{4}{|c|}{ Intervention group $(\mathrm{N}=171)$} & \multicolumn{4}{|c|}{ Control group $(\mathrm{N}=122)$} \\
\hline & Mean & SD & $\mathrm{N}$ & $\%$ & Mean & SD & $\mathrm{N}$ & $\%$ \\
\hline $\begin{array}{l}\text { Individual characteristics } \\
\text { Age (years) }\end{array}$ & 418 & 127 & & & 44.2 & 127 & & \\
\hline Gender (male) & 41.0 & 12.1 & 171 & 100 & 44.2 & 12.1 & 120 & 98 \\
\hline \multicolumn{9}{|l|}{ Education } \\
\hline Lower education & & & 127 & 74 & & & 103 & 84 \\
\hline Intermediate/higher education & & & 44 & 26 & & & 18 & 15 \\
\hline Missing & & & 1 & & & & 1 & \\
\hline \multicolumn{9}{|l|}{ Profession } \\
\hline Bricklayer & & & 39 & 23 & & & 16 & 13 \\
\hline Carpenter & & & 116 & 68 & & & 92 & 75 \\
\hline Other & & & 16 & 9 & & & 14 & 12 \\
\hline Work ability a & 15.8 & 2.2 & & & 15.4 & 2.5 & & \\
\hline \multicolumn{9}{|l|}{ Health status a } \\
\hline Physical & 50.2 & 8.2 & & & 49.4 & 8.9 & & \\
\hline Mental & 55.0 & 5.5 & & & 53.4 & 7.7 & & \\
\hline \multicolumn{9}{|l|}{ Musculoskeletal symptoms in the past seven days } \\
\hline Back & & & 34 & 20 & & & 29 & 24 \\
\hline Neck/shoulder & & & 23 & 13 & & & 15 & 13 \\
\hline Upper extremities & & & 21 & 12 & & & 16 & 13 \\
\hline Lower extremities & & & 32 & 19 & & & 22 & 19 \\
\hline Sick leave (6 months prior to the intervention) & 6.8 & 15.9 & & & 6.4 & 19.8 & & \\
\hline \multicolumn{9}{|c|}{ Number of sick leave days in the 6 months prior to baseline ${ }^{b}$} \\
\hline No or short-term sick leave ( $0-5$ days) & & & 128 & 75 & & & 99 & 83 \\
\hline Long term sick leave ( $\geq 6$ days) & & & 42 & 25 & & & 20 & 17 \\
\hline
\end{tabular}

a Higher score indicates a higher physical and mental health score, and a better work ability.

${ }^{b} \mathrm{P}<0.05$, indicating a significant differences between the intervention and control group at baseline.

cally significant results in the present study are in line with the findings of the short-term outcomes (ie, social support, need for recovery, work engagement, and physical workload) that were also not statistically significant in favor of the intervention group (data not shown).

First, the lack of impact on work ability might be explained by the broad concept of work ability as defined in the present study, including several individual characteristics and work-related factors (48). Even though the current intervention incorporated the physical and psychosocial factors into an intervention tailored to the construction workers (13), the dose (ie, four training sessions and the rest-break tool) might be insufficient to result in an effect on work ability and health. This is especially true when taking into account the workers' moderate compliance with the intervention (19). Of all workers in the intervention group, $61 \%$ followed at least three of the four training sessions and the majority of the workers did not complete the tool on a weekly basis. Moreover, it would be of interest to know which parts of the empowerment training sessions were applied in an effort to change the worker's behavior as this could explain the lack of effect. Unfortunately, because of the rapidly changing worksites, we were unable to detect which actions were taken as a result of the empowerment training sessions.

Second, the lack of impact of the intervention on work ability and health status may be due to the fact that we studied a relatively healthy group of workers.
At baseline, the mean scores of work ability and the physical and mental health status of the construction workers could be considered good $(49,50)$. Thus, by enrolling these workers, it was more difficult to detect an intervention effect on both primary outcomes. Moreover, physical and mental health status were measured using the SF-12, which is more commonly used among patient populations. To date, we have found no other intervention studies among workers including this outcome measure. Probably, this outcome is insufficiently sensitive to change within workers.

While no effects were found for physical health status, the preventive intervention showed a slight, but not significant, decline in musculoskeletal symptoms in favor of the intervention group. Both outcomes distinctively assessed the physical status of the construction workers but concerned different aspects (ie, daily limitations in physical functioning versus musculoskeletal symptoms). We found several intervention studies among workers with physically demanding jobs that implemented an integrated approach of several components (eg, group training session, individual education, and exercises) and investigated the effects on musculoskeletal symptoms $(45,47,51)$. All these studies failed to show a significant intervention effect on musculoskeletal symptoms as well. While a review showed no evidence of recommendations and devices to prevent back pain (52), the present study showed that individual advice about working techniques at the worksite is 
Table 2. Intervention effects on work ability and physical and mental health status between the intervention and control group after 3 , 6 , and 12 months of follow-up. a, b [95\% Cl=95\% confidence interval; ICC=intracluster correlation coefficient for clustering at company level.]

\begin{tabular}{|c|c|c|c|c|c|c|c|c|c|}
\hline & \multicolumn{3}{|c|}{ Intervention group } & \multicolumn{3}{|c|}{ Control group } & \multirow[t]{2}{*}{ ICC } & \multirow[t]{2}{*}{$ß$} & \multirow[t]{2}{*}{$95 \% \mathrm{Cl}^{\mathrm{c}}$} \\
\hline & $\mathrm{N}$ & Mean & SD & $\mathrm{N}$ & Mean & SD & & & \\
\hline Work ability d & & & & & & & 0.02 & & \\
\hline Baseline & 170 & 15.8 & 2.2 & 121 & 15.4 & 2.5 & & & \\
\hline 3-months & 134 & 15.7 & 1.8 & 92 & 15.4 & 2.2 & & 0.15 & $-0.31-0.62$ \\
\hline 6-months & 131 & 15.4 & 2.4 & 88 & 15.3 & 2.2 & & -0.26 & $-0.73-0.22$ \\
\hline 12-months & 115 & 15.5 & 2.1 & 89 & 15.1 & 2.3 & & 0.15 & $-0.34-0.63$ \\
\hline Overall effect & & & & & & & & 0.02 & $-0.34-0.37$ \\
\hline \multicolumn{10}{|l|}{ Health status ${ }^{d}$} \\
\hline Physical health status & & & & & & & 0.06 & & \\
\hline Baseline & 155 & 50.2 & 8.2 & 112 & 49.4 & 8.9 & & & \\
\hline 3-months & 121 & 51.4 & 7.1 & 85 & 50.7 & 7.5 & & 0.04 & $-1.77-1.85$ \\
\hline 6-months & 113 & 50.1 & 7.9 & 78 & 50.0 & 8.9 & & -0.39 & $-2.30-1.51$ \\
\hline 12-months & 104 & 49.8 & 8.4 & 80 & 49.2 & 8.1 & & 0.28 & $-1.65-2.20$ \\
\hline Overall effect & & & & & & & & -0.04 & $-1.43-1.35$ \\
\hline Mental health status & & & & & & & 0.01 & & \\
\hline Baseline & 155 & 55.0 & 5.5 & 112 & 53.4 & 7.7 & & & \\
\hline 3-months & 121 & 54.6 & 4.9 & 85 & 53.2 & 7.0 & & 0.63 & $-1.07-2.33$ \\
\hline 6-months & 113 & 54.1 & 7.2 & 78 & 53.5 & 5.8 & & 0.12 & $-1.65-1.89$ \\
\hline 12-months & 104 & 54.5 & 5.3 & 80 & 52.6 & 7.5 & & 1.71 & $-0.08-3.49$ \\
\hline Overall effect & & & & & & & & 0.80 & $-0.51-2.11$ \\
\hline
\end{tabular}

${ }^{a}$ Multilevel analyses were performed in which the clusters time, worker and company were taken into account.

${ }^{b}$ For all analyses, eight departments in the intervention group and seven departments of the control group within the six companies were included.

${ }^{c}$ Adjusted model corrected for age and education.

A A positive $\beta$ means higher work ability, physical and mental health status in the intervention group compared to the control group.

promising in preventing musculoskeletal symptom (ie, neck pain and lower extremities). It could be argued that the present study provided insufficient dose regarding the training sessions of the physical therapists, which led to non-significant improvements in the outcomes. In order to achieve a behavioral change with regard to working techniques and rest breaks, and consequently a decline in the prevalence of musculoskeletal symptoms, it could be hypothesized that a longer duration or a higher frequency of the training sessions from the physical therapist are needed.

With regard to sick leave, a favorable decline on the prevalence of long-term sick leave at 6 and 12 months follow-up was found in favor of the intervention group. As expected, the power of the study population was insufficient to detect a statistically significant effect on sick leave. At the start of the project, a power analysis was based on finding an effect on health status, which was our primary outcome measure. Sick leave data have a skewed distribution and a large standard deviation. As a consequence, a large sample size is needed, which is not often feasible in studies such as randomized controlled trials. The beneficial decline in the present study was not in accordance with other intervention programs among blue-collar workers $(45,53,54)$ that revealed no differences in sick leave at all. It is hypothesized that the reduction in long-term sick leave could be attributed to the beneficial decline in musculoskeletal symptoms in the intervention group. Unfortunately, data from the personnel administration of the six participating companies did not include sick leave diagnoses, which hampered the interpretation of the sick leave data in the present study.

Although construction worksites are temporary and mobile, the current study illustrated the feasibility of a preventive intervention at these worksites. However, the worksite intervention consisting of individual training sessions of a physical therapist, the use of rest-break tool, and two empowerment training sessions did not result in improvements on the primary outcomes (work ability and physical and mental health). Therefore, the intervention should not be implemented directly on a larger scale in the Dutch construction industry. Considering the moderate-tohigh satisfaction of the workers vis-à-vis the training sessions of the physical therapist (19) and the slight decline in the prevalence of musculoskeletal symptoms, these training sessions seem promising but require more research. It is recommended to further investigate if sessions of a longer duration or a higher frequency would lead to a significant decline in the prevalence of musculoskeletal symptoms and long-term sick leave. More research is also needed to identify factors to keep construction workers healthy in the future and prevent early retirement. Based on these factors, it might be possible that more comprehensive actions are needed to promote work ability and health, including organizational and environmental interventions. Additionally, the intervention targeted construction workers individually. As 
Table 3. Intervention effects on musculoskeletal symptoms and sick leave between the intervention and control group. ${ }^{\mathrm{a}, \mathrm{b}}$ [OR=0dds ratio; $95 \% \mathrm{Cl}=95 \%$ confidence interval]

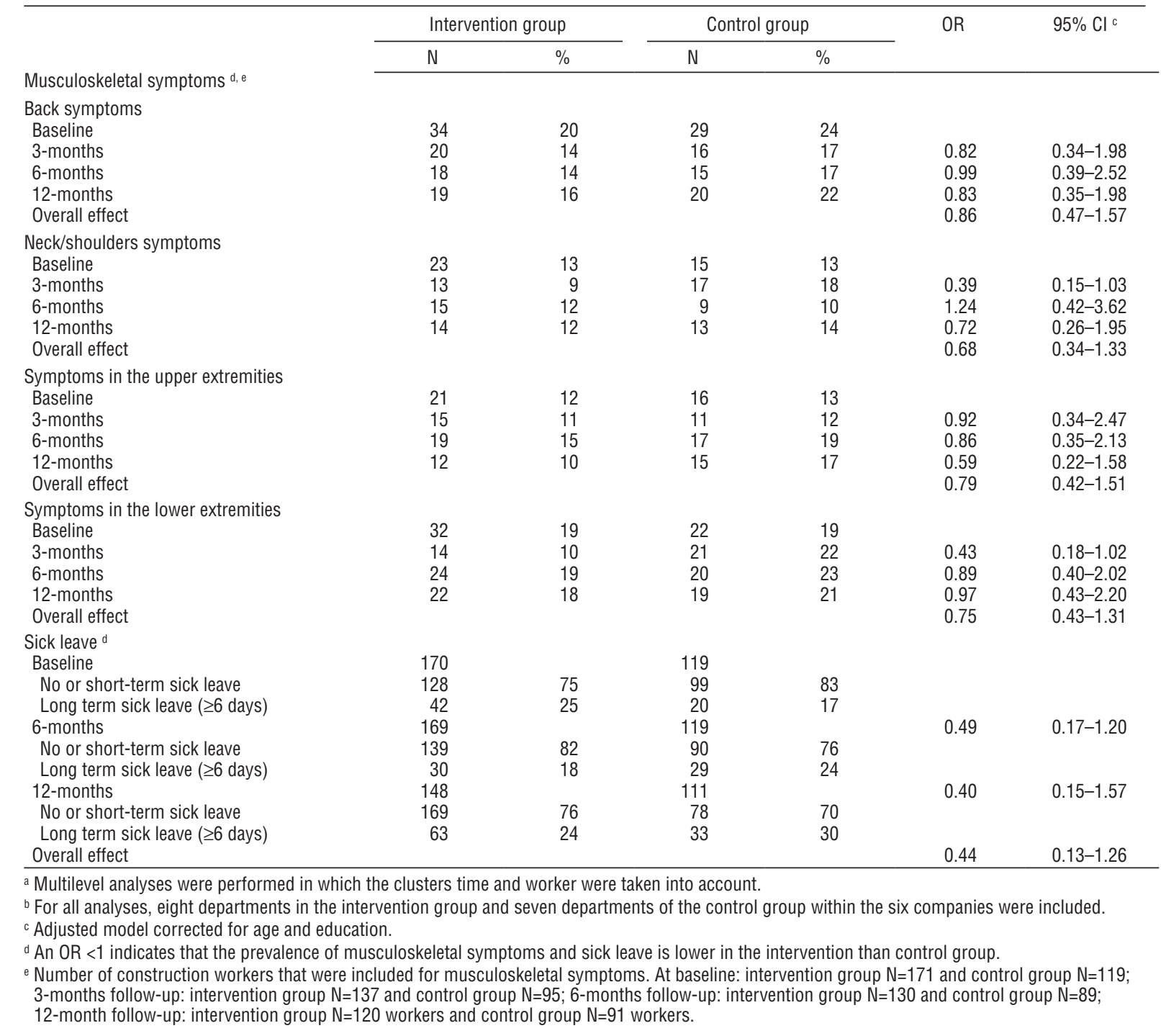

postponing early retirement could be facilitated by increasing social support from colleagues and supportive leadership (55), future interventions should put more emphasis on a comprehensive multidisciplinary approach by actively involving supervisors and managers.

\section{Concluding remarks}

As a shortage of construction workers is expected in the next decades, effective intervention programs are needed to promote a healthy working life and prevent early retirement. The results of the preventative program in this study showed no effects on work ability, physical and mental health status. The effectiveness with respect to the prevalence of musculoskeletal symptoms and long-term sick leave was in favor of the intervention group, although the differences between the intervention and control group were not statistically significant.

\section{Acknowledgments}

The Netherlands Organization for Health Research and Development (ZonMw) funded this project (12051.0004). We thank the human resource managers of the companies for collecting sick leave data and acknowledge all the participating construction workers. The authors declare no competing interests. The trial is registrated as NTR1278. 


\section{References}

1. Beereboom HJA, Blomsma G, Corten IW, Muchall S. De bouwarbeidsmarkt in de periode 2005-2010 [The labor market of the construction industry in the period 2005-2010]. Amsterdam: Economisch Instituut voor de Bouw; 2005.

2. Sijpersma R. De oudere werknemer in de bouw. [The older worker in the construction industry]. Amsterdam: Economisch Instituut voor de Bouw; 2003.

3. Alavinia SM, Van den Berg TI, Van Duivenbooden C, Elders LA, Burdorf A. Impact of work-related factors, lifestyle, and work ability on sickness absence among Dutch construction workers. Scand J Work Environ Health. 2009; 35(5):325-33. http://dx.doi.org/10.5271/sjweh.1340.

4. Alavinia SM, de Boer AG, van Duivenbooden JC, FringsDresen MH, Burdorf A. Determinants of work ability and its predictive value for disability. Occup Med (Lond). 2009 Jan;59(1):32-7. http://dx.doi.org/10.1093/occmed/kqn148.

5. Ybema JF, Geuskens GA, Oude Hengel KM. Oudere werknemers en langer doorwerken [Older employees and prolonging working life]. Hoofddorp: Netherlands Organisation for Applied Scientific Research TNO; 2010.

6. Sell L. Predicting long-term sickness absence and early retirement pension from self-reported work ability. Int Arch Occup Environ Health. 2009;82(9):1133-8. http://dx.doi. org/10.1007/s00420-009-0417-6.

7. Liira J, Matikainen E, Leino-Arjas P, Malmivaara A, Mutanen $\mathrm{P}$, Rytkönen $\mathrm{H}$, et al. Work ability of middle-aged finnish construction workers- a follow-up study in 1991-1995. Int J Ind Erg. 2000;25(5):477-81. http://dx.doi.org/10.1016/ S0169-8141(99)00032-3.

8. Oude Hengel KM, Blatter BM, Geuskens GA, Koppes LLJ, Bongers PM. Factors associated with the ability and willingness to continue working until the age of 65 in construction workers. Int Arch Occup Environ Health. 2011; 85(7):783-90. http:// dx.doi.org/10.1007/s00420-011-0719-3.

9. Lund T, Iversen L, Poulsen KB. Work environment factors, health, lifestyle and marital status as predictors of job change and early retirement in physically heavy occupations. Am J Ind Med. 2001;40(2):161-9. http://dx.doi.org/10.1002/ ajim. 1084 .

10. Brenner H, Ahern W. Sickness absence and early retirement on health grounds in the construction industry in ireland. Occup Environ Med. 2000;57(9):615-20. http://dx.doi.org/10.1136/ oem.57.9.615.

11. De Boer AG, Burdorf A, Van Duivenbooden C, Frings-Dresen $\mathrm{MH}$. The effect of individual counselling and education on work ability and disability pension: A prospective intervention study in the construction industry. Occup Environ Med. 2007;64(12):792-7. http://dx.doi.org/10.1136/ oem.2006.029678.

12. Oude Hengel KM, Joling CI, Proper KI, Van der Molen HF, Bongers PM. Using intervention mapping to develop a worksite prevention program for construction workers. Am J Health Promot. 2010;26:e1-e10. http://dx.doi.org/10.4278/
ajhp.100326-QUAL-88.

13. Oude Hengel KM, Joling CI, Proper KI, Blatter BM, Bongers PM. A worksite prevention program for construction workers: Design of a randomized controlled trial. BMC Public Health. 2010 Jun 14;10:336. http://dx.doi.org/10.1186/1471-245810-336.

14. Boschman JS, Van der Molen HF, Sluiter JK, Frings-Dresen $\mathrm{MH}$. Musculoskeletal disorders among construction workers: A one-year follow-up study. BMC Musculoskelet Disord. 2012 Oct 13;13:196. http://dx.doi.org/10.1186/1471-2474-13-196.

15. Stocks SJ, Turner S, McNamee R, Carder M, Hussey L, Agius RM. Occupation and work-related ill-health in UK construction workers. Occup Med (Lond). 2011;61(6):407-15. http://dx.doi.org/10.1093/occmed/kqr075.

16. Alavinia SM, Van Duivenbooden C, Burdorf A. Influence of work-related factors and individual characteristics on work ability among dutch construction workers. Scand J Work Environ Health. 2007;33(5):351-7. http://dx.doi.org/10.5271/ sjweh.1151.

17. Boschman JS, Van der Molen HF, Sluiter JK, Frings-Dresen MH. Occupational demands and health effects for bricklayers and construction supervisors: A systematic review. Am J Ind Med. 2011;54(1):55-77. http://dx.doi.org/10.1002/ ajim.20899.

18. DeZwart BCH, Frings-Dresen MH, Van Duivenbooden JC. Senior workers in the Dutch construction industry: A search for agerelated work and health issues. Exp Aging Res. 1999;25(4):38591. http://dx.doi.org/10.1080/036107399243841.

19. Oude Hengel KM, Blatter BM, Van der Molen HF, Joling CI, Proper KI, Bongers PM, et al. Meeting the challenges of implementing an intervention to promote work ability and health-related quality of life at construction worksites: A process evaluation. J Occup Environ Med. 2011;53(12):148391. http://dx.doi.org/10.1097/JOM.0b013e3182398e03.

20. Ware JEJ. SF-36 health survey update. Spine. 2000;25(24):3130 9. http://dx.doi.org/10.1097/00007632-200012150-00008.

21. Aaronson NK, Muller M, Cohen PD, Essink-Bot ML, Fekkes M, Sanderman R, et al. Translation, validation, and norming of the Dutch language version of the SF-36 health survey in community and chronic disease populations. J Clin Epidemiol. 1998;51(11):1055-68. http://dx.doi.org/10.1016/S08954356(98)00097-3.

22. Beaton DE, Hogg-Johnson S, Bombardier C. Evaluating changes in health status: Reliability and responsiveness of five generic health status measures in workers with musculoskeletal disorders. J Clin Epidemiol. 1997;50(1):79-93. http://dx.doi. org/10.1016/S0895-4356(96)00296-X.

23 Simpson JM, Klar N, Donnor A. Accounting for cluster randomization: A review of primary prevention trials, 1990 through 1993. Am J Public Health. 1995;85(10):1378-83. http://dx.doi.org/10.2105/AJPH.85.10.1378.

24. Cohen J. Statistical power analysis for the behavioral sciences. New Jersey: Lawrence Erlbaum Associates; 1988.

25. Bartholomew LK, Parcel GS, Kok G, Gottlieb NH. Planning health programs: An intervention mapping approach. San 
Francisco: Jossey-Bass; 2006.

26. Ilmarinen J. Ageing workers in the European union - status and promotion of work ability, employability and employment. Helsinki: Finnish Institute of Occupational Health, Ministry of Social Affairs and Health, Ministry of Labour; 1999.

27. De Zwart BC, Frings-Dresen MH, Van Duivenbooden JC. Test-retest reliability of the work ability index questionnaire. Occup Med (Lond). 2002;52(4):177-81. http://dx.doi. org/10.1093/occmed/52.4.177.

28. Eskelinen L, Kohvakka A, Merisalo T, Hurri H, Wagar G. Relationship between the self-assessment and clinical assessment of health status and work ability. Scand J Work Environ Health. 1991;17 Suppl 1:S40-7.

29. Ahlstrom L, Grimby-Ekman A, Hagberg M, Dellve L. The work ability index and single-item question: Associations with sick leave, symptoms, and health--a prospective study of women on long-term sick leave. Scand J Work Environ Health. 2010;36(5):404-12. http://dx.doi.org/10.5271/sjweh.2917.

30. Torgén M. Experiences of WAI in a random sample of the Swedish working population. International Congress Series. 2005;1280:328-32. http://dx.doi.org/10.1016/j. ics.2005.01.016

31. Tuomi K, Ilmarinen J, Jahkola A, Katajarinne L, Tulkki A. Work ability index. Helsinki: Finnish Institute of Occupational Health; 1998

32. Jenkinson C, Layte R. Development and testing of the UK SF-12 (short form health survey). J Health Serv Res Policy. 1997;2(1):14-8.

33. Ware JJ, Kosinski M, Keller SD. A 12-item short-form health survey: construction of scales and preliminary tests of reliability and validity. Med Care. 1996;34(3):220-33. http:// dx.doi.org/10.1097/00005650-199603000-00003.

34. Saris-Baglama RN, Dewey CJ, Chisholm GB, Plumb E, King J, Kosinski M, et al. QualityMetric health outcomes scoring software 3.0: User's guide. Lincoln: QualityMetric Incorporated; 2009.

35. Gandek B, Ware JE, Aaronson NK, Apolone G, Bjorner JB, Brazier JE, et al. Cross-validation of item selection and scoring for the SF-12 health survey in nine countries: Results from the IQOLA project. international quality of life assessment. J Clin Epidemiol. 1998;51(11):1171-8. http://dx.doi.org/10.1016/ S0895-4356(98)00109-7.

36. Hildebrandt VH. Prevention of musculoskeletal disorders [thesis]. Amsterdam: VU University; 2001.

37. Hildebrandt VH, Bongers PM, Van Dijk FJ, Kemper HC, Dul J. Dutch musculoskeletal questionnaire: Description and basic qualities. Ergonomics. 2001;44(12):1038-55. http://dx.doi. org/10.1080/00140130110087437.

38. Twisk JWR. Applied multilevel analysis. Cambridge: Cambridge University Press; 2006. http://dx.doi.org/10.1017/ CBO9780511610806.

39. Szubert Z, Sobala W. Current determinants of early retirement among blue collar workers in poland. Int J Occup Med Environ Health. 2005;18(2):177-84.

40. Gram B, Holtermann A, Sogaard K, Sjogaard G. Effect of individualized worksite exercise training on aerobic capacity and muscle strength among construction workers - a randomized controlled intervention study. Scand J Work Environ Health. 2012;38(5):467-75. http://dx.doi. org/10.5271/sjweh.3260.

41. Groeneveld IF, Proper KI, Van der Beek AJ, Hildebrandt VH, Van Mechelen W. Short and long term effects of a lifestyle intervention for construction workers at risk for cardiovascular disease: A randomized controlled trial. BMC Public Health. 2011 Oct 31;11:836. http://dx.doi.org/10.1186/1471-2458$11-836$.

42. Ludewig PM, Borstad JD. Effects of a home exercise programme on shoulder pain and functional status in construction workers. Occup Environ Med. 2003;60(11):8419. http://dx.doi.org/10.1136/oem.60.11.841.

43. Luijsterburg PA, Bongers PM, de Vroome EM. A new bricklayers' method for use in the construction industry. Scand J Work Environ Health. 2005;31(5):394-400. http://dx.doi. org/10.5271/sjweh.923.

44. Ivers NM, Taljaard M, Dixon S, Bennett C, McRae A, Taleban $\mathrm{J}$, et al. Impact of CONSORT extension for cluster randomised trials on quality of reporting and study methodology: Review of random sample of 300 trials, 2000-8. BMJ. 2011 Sep 26;343:d5886. http://dx.doi.org/10.1136/bmj.d5886.

45. Jorgensen MB, Faber A, Hansen JV, Holtermann A, Sogaard $\mathrm{K}$. Effects on musculoskeletal pain, work ability and sickness absence in a 1-year randomised controlled trial among cleaners. BMC Public Health. 2011 Nov 1;11:840. http:// dx.doi.org/10.1186/1471-2458-11-840.

46. Nurminen E, Malmivaara A, Ilmarinen J, Ylostalo P, Mutanen $\mathrm{P}$, Ahonen $\mathrm{G}$, et al. Effectiveness of a worksite exercise program with respect to perceived work ability and sick leaves among women with physical work. Scand J Work Environ Health. 2002;28(2):85-93. http://dx.doi.org/10.5271/ sjweh.652.

47. IJzelenberg H, Meerding WJ, Burdorf A. Effectiveness of a back pain prevention program: A cluster randomized controlled trial in an occupational setting. Spine. 2007;32(7):711-9. http://dx.doi.org/10.1097/01.brs.0000259072.14859.d9.

48. Ilmarinen J. Work ability, a comprehensive concept for occupational health research and prevention. Scand J Work Environ Health. 2009;35(1):1-5. http://dx.doi.org/10.5271/ sjweh.1304.

49. Gould R, Ilmarinen J, Järvisalo J, Koskinen S. Dimension of work ability: Results of the health 2000 survey. Helsinki: Finnish Institute of Occupational Health; 2008.

50. Welch LS, Haile E, Boden LI, Hunting KL. Impact of musculoskeletal and medical conditions on disability retirement-a longitudinal study among construction roofers. Am J Ind Med. 2010;53(6):552-60.

51. Haukka E, Leino-Arjas P, Viikari-Juntura E, Takala EP, Malmivaara A, Hopsu L, et al. A randomised controlled trial on whether a participatory ergonomics intervention could prevent musculoskeletal disorders. Occup Environ Med. 2008;65(12):849-56. http://dx.doi.org/10.1136/ oem.2007.034579. 
52. Verbeek J, Martimo KP, Karppinen J, Kuijer PP, Takala EP, Viikari-Juntura E. Manual material handling advice and assistive devices for preventing and treating back pain in workers: A Cochrane systematic review. Occup Environ Med. 2012;69(1):79-80. http://dx.doi.org/10.1136/ oemed-2011-100214.

53. Haukka E, Leino-Arjas P, Viikari-Juntura E, Takala EP, Malmivaara A, Hopsu L, et al. A randomised controlled trial on whether a participatory ergonomics intervention could prevent musculoskeletal disorders. Occup Environ Med. 2008;65(12):849-56. http://dx.doi.org/10.1136/ oem.2007.034579.
54. IJzelenberg W, Molenaar D, Burdorf A. Different risk factors for musculoskeletal complaints and musculoskeletal sickness absence. Scand J Work Environ Health. 2004;30(1):56-63. http://dx.doi.org/10.5271/sjweh.765.

55. Van den Berg TI, Elders LA, Burdorf A. Influence of health and work on early retirement. J Occup Environ Med. 2010;52(6):576-83. http://dx.doi.org/10.1097/ JOM.0b013e3181de8133.

Received for publication: 4 June 2012 